Anales de Geografía de la Universidad Complutense ISSN: 0211-9803

http://dx.doi.org/10.5209/AGUC. 62484

\title{
Patrones de consumo de agua en usos turístico-residenciales en la costa de Alicante (España) (2005-2015). Una tendencia desigual influida por la tipología urbana y grado de ocupación ${ }^{1}$
}

\author{
Álvaro Francisco Morote Seguido ${ }^{2}$; María Hernández Hernández ${ }^{3}$; Antonio Manuel Rico \\ Amorós ${ }^{4}$
}

Recibido: 8 de febrero del 2017/ Enviado a evaluar: 9 de mayo del 2017/ Aceptado: 18 de octubre del 2018

Resumen. El litoral mediterráneo español ha vivido un importante crecimiento urbano relacionado con la actividad turística desde 1960. El objetivo de esta investigación es analizar y caracterizar la tendencia del gasto de agua en la costa de Alicante (2005-2015), teniendo en cuenta la repercusión del aumento de viviendas y usuarios conectados a la red durante el último boom inmobiliario (1997-2008). Para ello, se han analizado datos de facturación de agua potable por vivienda en función de las diferentes tipologías urbano-residenciales y tipo de ocupación, y un análisis del consumo en hoteles. Entre las conclusiones cabe mencionar que se ha producido un cambio de tendencia a partir de mediados de la década del 2000 con una reducción del consumo y la verificación de pautas distintas en los módulos de gasto de agua. Se detecta, asimismo, que en determinadas tipologías de marcada función turístico-residencial se ha producido una moderada recuperación del consumo de agua desde 2010.

Palabras clave: Agua; patrones; consumo; tipología urbana; turismo; Alicante.

1 Este artículo se inserta en el proyecto de investigación "Uso y Gestión de recursos hídricos no convencionales en el litoral de las regiones de Valencia y Murcia como estrategia de adaptación a la sequía” (CSO2015-65182-C2-2P) financiado por el Ministerio de Economía y Competitividad y resultado de la concesión de una beca predoctoral de Formación de Profesorado Universitario del Programa Nacional de Investigación Científica, Desarrollo e Innovación Tecnológica (FPU).

2 Instituto Interuniversitario de Geografía. Universidad de Alicante.

E-mail: alvaro.morote@ua.es

3 Instituto Interuniversitario de Geografía. Universidad de Alicante.

E-mail: maria.hernandez@ua.es

4 Instituto Interuniversitario de Geografía. Universidad de Alicante.

E-mail: am.rico@ua.es 


\title{
[en] Patterns of tourism and residential water consumption on the coast of Alicante (Spain) (2005-2015). A trend unequally influenced by urban typology and occupation.
}

\begin{abstract}
The Spanish Mediterranean coastline has experienced a significant urban growth related to tourist activity since 1960 . The aim of this research is to define and to analyse water consumption trend along the coast of province of Alicante (2005-2015), taking into account a hypothetical increase in water consumption due to the increase in dwelling and users connected to the network during the last real estate bubble (1997-2008). To do this, real billing data of dwelling were analysed according to the different urban typologies and type of occupation and an analysis of hotels consumption. The conclusions drawn include facts as there has been a change of trend from the middle of the 2000s and water consumption has been fell since the mid-2000s. In addition, it is also detected that a slight increase of water consumption has produced in certain typologies of tourist and residential function since 2000 .
\end{abstract}

Key words: Water; patterns; consumption; urban typologies; tourism; Alicante.

\section{[fr] Les modes de consommation de l'eau dans les utilisations touristiques et résidentielles sur la côte d'Alicante (Espagne) (2005-2015). Une tendance inégale influencée par type urbain et d'occupation.}

Résumé. La côte méditerranéenne espagnole a connu une croissance urbaine très important en relation avec le tourisme depuis 1960. L'objectif de cette recherche est d'analyser et de caractériser l'évolution de la consommation d'eau à la côte d'Alicante (Sud-Est d'Espagne) (2005-2015), en prenant en compte l'impact de la croissant de logements et les utilisateurs connectés au réseau pendant le dernier boom immobilier (1997-2008). À cette fin, nous avons analysé la facturation de l'eau potable par ménage en fonction des différentes typologies résidentielles urbaines et le type d'occupation et une analyse de la consommation d'eau dans les hôtels. Parmi les résultats comprennent qu'il y a eu un changement de tendance à partir du milieu des années 2000 avec une réduction de la consommation et la vérification des différents modèles de la consommation d'eau. En plus, nous avons détecte aussi que certains types urbaines de fonction touristique et résidentielle ont été une reprise modérée de la consommation d'eau depuis 2010.

Mots clé: L'eau; modes; consommation; typologie urbaines; tourisme; Alicante.

Cómo citar. Morote Seguido, A.F., Hernández Hernández, M. y Rico Amorós, A.M. (2018): Patrones de consumo de agua en usos turístico-residenciales en la costa de Alicante (España) (2005-2015). Una tendencia desigual influida por la tipología urbana y grado de ocupación. Anales de Geografía de la Universidad Complutense, 38(2), 357-383

Sumario. 1. Introducción. 2. Área de estudio y metodología. 3. Resultados. 3.1. Una tendencia general de disminución del consumo de agua influida por factores estructurales y coyunturales. 3.2. La evolución del consumo de agua en viviendas urbano-turísticas. Una tendencia influida por las tipologías urbanas y la ocupación estacional. 3.3. La evolución del consumo de agua en establecimientos hoteleros. Una tendencia influida por la categoría y el comportamiento de la actividad turística. 4. Discución y conclusiones. 5. Bibliografía.

\section{Introducción}

El notable incremento del consumo de agua para usos urbano-turísticos en el litoral mediterráneo europeo se ha producido, en gran medida, a partir de 1960 hasta llegar a 
registrar picos máximos a finales de la década de 1990 y principios del 2000 (Gil et al., 2015). Este aumento se relaciona con la espectacular expansión de viviendas y población que ha registrado este territorio costero ligado a la difusión de las funciones turístico-residenciales, de ocio y de servicios (Gössling, 2015). En gran medida, el aumento de la superficie urbano-residencial se ha basado en modelos de poblamiento extensivos caracterizados por la presencia de elementos externos como son jardines y piscinas (Morote 2016a). Este proceso de urbanización se ha implantado en áreas turísticas y residenciales de EE.UU. (Leichenko y Solecki, 2005), Australia (Loh y Coghlan, 2003) y en gran parte de la costa mediterránea francesa (Fernández y Barrado, 2011), italiana (Romano et al., 2014), griega (Panagopoulos, 2014) y española, con particular intensidad en las Islas Baleares (Salvà, 2002), la Costa del Sol (Andalucía) (Raya \& Benítez, 2002) y el Sureste Ibérico (Burriel, 2008). Esta región climática se caracteriza por la escasez de recursos hídricos y por registrar elevadas demandas de agua tanto para usos urbano-turísticos como agrícolas (Rico et al., 2014).

En numerosos municipios litorales del mediterráneo europeo, ya desde los años sesenta del pasado siglo, se ha llevado a cabo el proceso de modernización de las funciones productivas apoyándose en el llamado turismo residencial (Vera, 1987). En España, este concepto se ha utilizado desde finales de los años setenta para explicar los cambios sociales, económicos y territoriales generados por el incremento de dos formas de movilidad humana como son el turismo y la migración (Mantecón et al., 2016). Por lo tanto, esta actividad se asocia, por un lado, a las formas de veraneo tradicionales y, por otra, a nuevos estilos de vida y de movilidad residencial vinculados a la construcción masiva de segundas residencias (Membrado, 2015). Ligado a la vivienda secundaria para uso vacacional, se relacionan diferentes modelos de urbanización basados en la construcción, la venta y el alquiler que ha caracterizado de manera general a la costa mediterránea española hasta el estallido de la burbuja inmobiliaria en 2008. En este sentido, en esta área, en el periodo comprendido entre 1992 y el año 2000, se construyeron 1,2 millones de viviendas, incrementándose en 5 millones más entre el 2001 y el 2011, lo que representó un aumento del $25 \%$ sobre el total del parque de viviendas (Ministerio de Fomento, 2012). En la provincia Alicante, entre 1997 y 2008 se edificaron 345.410 nuevas viviendas, ocupando el tercer puesto en el ranking nacional por detrás de Madrid y Barcelona y superando a provincias con un mayor peso demográfico (Hernández et al., 2015).

En relación con el consumo de agua para usos urbanos y turísticos, los estudios llevados a cabo en diversos países del Norte y Centro de Europa (Schleich y Hillenbrand, 2007), California (Cohen et al., 2004), Chile (Durán, 2015), Chipre (Hadjikakou et al., 2015) o Madrid (España) (Cubillo et al., 2008) ponen de manifiesto ciertas diferencias en su distribución vinculadas a factores urbanos, sociales, económicos, sociológicos y ambientales. Significativa resulta la vinculación del incremento del gasto de agua en tipologías urbanas caracterizadas por la presencia de jardines y piscinas (Vidal et al., 2011; Morote et al., 2017). En Australia, por ejemplo, Hurd (2006) llegó a la conclusión de que el riego del jardín suponía más del $50 \%$ del total del agua consumida en el hogar. En el caso español, esta relación se ha 
puesto de manifiesto en estudios llevados a cabo en el Área Metropolitana de Barcelona (March y Saurí, 2016), Girona (García, 2012) o el litoral de Alicante (Morote, 2017).

El interés por analizar las relaciones entre usos turísticos y consumo de agua en el litoral de Alicante se justifica porque este territorio se ha caracterizado por ser una de las áreas donde mayor ha sido la expansión del poblamiento urbano-turístico y presenta, además, una fuerte dependencia de volúmenes de agua proporcionados por ríos alóctonos (Segura), acuíferos y procedentes del Acueducto Tajo-Segura (ATS) (1979) para poder garantizar tanto las demandas urbanas como agrícolas (March et al., 2014). Más recientemente, desde 2003, se ha potenciado la construcción de plantas desalinizadoras lo que ha originado un amplio debate en torno al sobredimensionamiento de su capacidad de producción y al elevado coste económico de este recurso alternativo (Swyngedouw y Williams, 2016). Cabe indicar, sin embargo, que, debido al cierre del ATS desde mayo de 2017 por la sequía que padece la cabecera del Tajo y por unas nuevas normas de explotación más conservadoras, la desalinización se ha convertido en un recurso de vital importancia que está garantizando el suministro de agua en el litoral y prelitoral del sureste peninsular, haciendo de este recurso, una fuente hídrica estratégica.

También cabe señalar que los estudios sobre tipologías urbanas y su relación con el gasto de agua en el área de estudio seleccionada son escasos y relativamente recientes. En cambio, si se han llevado a cabo este tipo de investigaciones en otras áreas del ámbito mediterráneo español como en el Área Metropolitana de Barcelona (Domene y Saurí, 2006) o Girona (García, 2012). En la provincia de Alicante, ha habido una importante producción científica en relación con la demanda de agua y turismo (Baños et al., 2010) y recientemente los que analizan las repercusiones de jardines y piscinas en el consumo de agua (Morote y Hernández, 2016a; Morote et al., 2017). Como referencias a esta línea de investigación cabe reseñar los trabajos de Rico (2007), Rico et al., (2009) y Olcina et al., (2016), donde se analizaron los consumos por tipología urbana, tipo de ocupación y el consumo de determinados establecimientos (hoteles, restaurantes, lavanderías, etc.) en la ciudad de Benidorm y los de Gil et al., (2015) y Morote et al., (2016) para la ciudad de Alicante con datos sobre consumos por barrios y tipologías urbanas entre 2007-2013.

La hipótesis de partida de esta investigación pretende validar si el notable incremento de viviendas y, por tanto, de hogares conectados a la red de distribución de agua potable en los últimos años (2005-2015) ha significado un aumento del consumo de agua y, de esta manera, poder evidenciar si ese gasto por hogar varía en función de la tipología urbana y tipo de ocupación. Por tanto, los objetivos de este trabajo son: a) analizar y caracterizar la tendencia del consumo de agua para usos urbano-turísticos en la costa de la provincia de Alicante; b) examinar y determinar la tendencia del gasto de agua en función de las tipologías urbanas y tipo de ocupación por municipio; c) analizar la evolución del consumo de agua en hoteles en función de su categoría; y d) identificar los factores que inciden en la tendencia del gasto de agua actual y determinar las relaciones que se establecen entre consumo de agua, urbanización y estacionalidad. 


\section{2. Área de estudio y metodología}

La actividad turística y el poblamiento de segundas residencias han producido un cambio en el modelo urbano y demográfico en los municipios de la fachada mediterránea europea. La provincia de Alicante, y más concretamente su ámbito litoral, es un claro ejemplo de ello. A pesar de que las características climáticas lo sitúan como uno de los ámbitos más áridos de España (Olcina y Miró, 2016) con precipitaciones medias que, en la ciudad de Alicante ascienden a $356 \mathrm{~mm} / \mathrm{año}$, un régimen térmico benigno y la elevada insolación con más de 2.800 horas efectivas de sol al año, le otorgan a este territorio grandes ventajas de confort climático para albergar actividades turísticas, de ocio y de función residencial (Gil y Rico, 2007). Ello ha favorecido la expansión de tipologías urbanas de baja densidad desde la década de los años sesenta con predominio de población extranjera europea procedente del Centro y Norte de Europa que adquirieron una vivienda en este territorio por motivos turístico-residenciales (Morote y Hernández, 2016b). El análisis de este proceso territorial y socio-económico reviste extraordinario interés, particularmente en lo que concierne a las relaciones que se establecen entre consumos hídricos y factores que inciden en esa demanda como pueden ser las tipologías urbanas y grado de la ocupación del hogar en el área de estudio.

Para esta investigación se han seleccionados 5 municipios representativos del modelo urbano de la costa de Alicante (l'Alfàs del Pi, Alicante, Benidorm, Rojales y Torrevieja) (Figura 1) que se caracterizan por el predominio de tipologías urbanas vinculadas al poblamiento turístico y de segundas residencias, si bien con diferencias significativas entre ellos. En el litoral Norte, es mayoritaria la urbanización de baja densidad (chalés), que representan el 69\% del total de la superficie ocupada por suelo urbano (caso de l'Alfàs del Pi), mientras que en la costa Sur predominan las urbanizaciones de viviendas adosadas (25\%) y chalés (37\%), aunque en parcelas de menor tamaño (Rojales y Torrevieja) (Morote, 2014). Estos dos modelos se completan con aquellos municipios que presentan un claro predominio de la oferta de alojamiento hotelero y de apartamentos como es Benidorm (Rico et al., 2009) y aquéllos en los que prevalecen las funciones de servicios y la oferta de apartamentos turísticos (segundas residencias) en su franja litoral (ciudad de Alicante). Un segundo factor que se ha tenido en cuenta en la selección de estos municipios es el proceso de implantación de las actividades turístico-residenciales. En la costa septentrional, se inicia a partir de la década de 1960. En el Sur, aunque registró un desarrollo localizado en la localidad de Torrevieja en los años setenta, la mayor intensidad se produce a partir de 1990. El diferente periodo de implantación determina, a su vez, el predominio de unas tipologías u otras y el ámbito territorial donde se desarrollan. En una primera fase, su expansión afectó a ámbitos estrictamente litorales para luego difundirse hacia municipios de interior asociado a la saturación y pérdida de calidad paisajística de la costa (Morote y Hernández, 2016c). 
Figura 1. Área de estudio

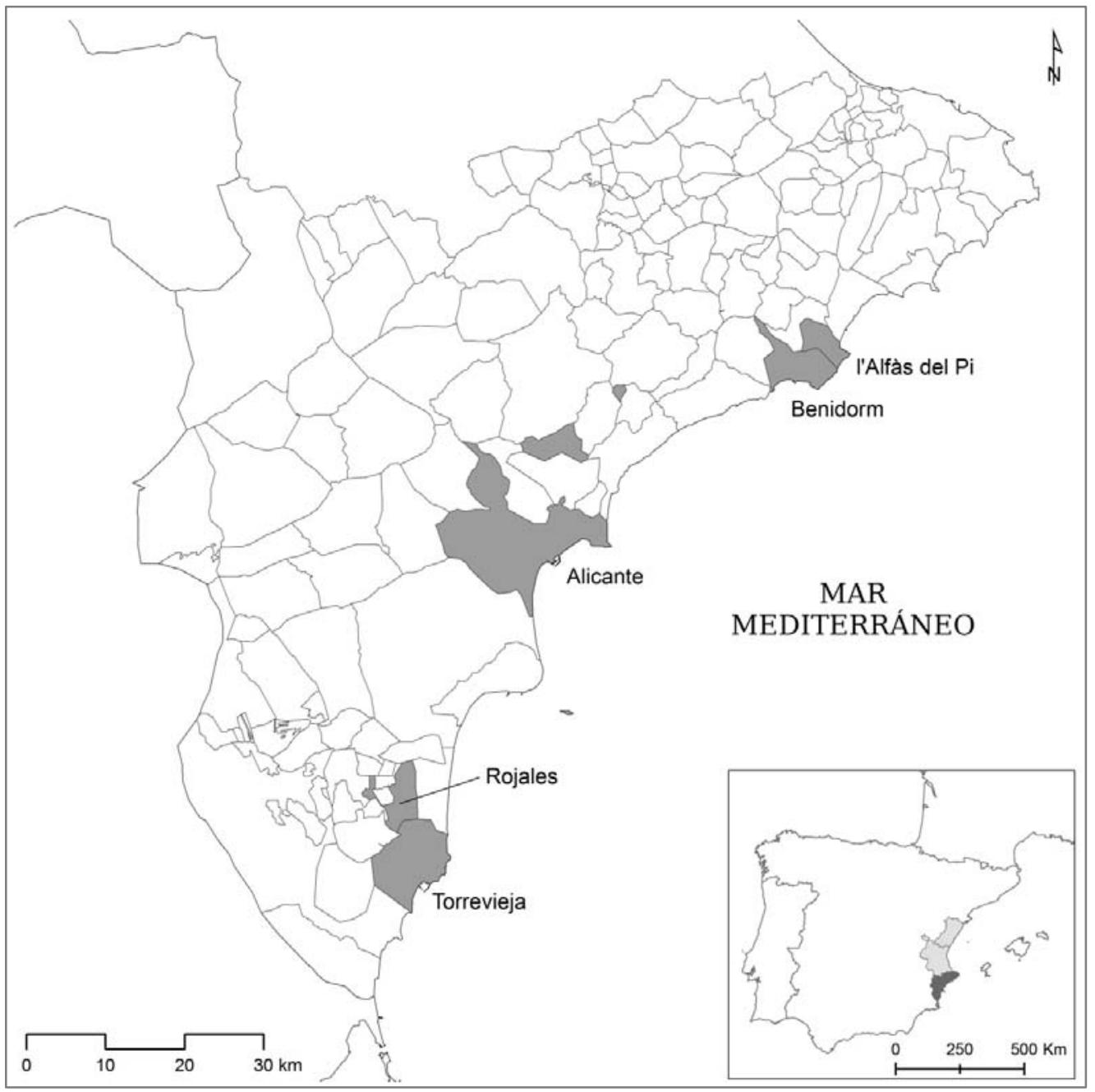

Fuente: Elaboración propia.

El tercer factor considerado ha sido la presencia de población extranjera europea procedente del Centro y Norte de Europa. Los denominados "emigrantes climáticos", es decir, aquéllos que eligen este territorio por confort térmico, constituyen otra de las peculiaridades de este ámbito (Casado et al., 2014). A nivel provincial, el número de europeos extranjeros excede los 330.000 habitantes, representando el $17 \%$ de la población total de la provincia, siendo la británica la nacionalidad más numerosa (93.043 residentes) (INE, 2011). Si se analiza a escala municipal, se observan diferencias significativas en relación con el porcentaje que ésta representa. En este sentido, en la costa norte, oscila entre el $17 \%$ en Benidorm (12.040 extranjeros 
europeos) y el 50\% como, por ejemplo, en l'Alfàs del Pi con el 52,66\% (10.427 extranjeros europeos). En cambio, en el sector meridional de Alicante, estos porcentajes, de manera generalizada, superan el 50\%; alcanzándose valores en torno al $70 \%$ en municipios como Rojales con el 71,54\% (12.868 extranjeros europeos) (INE, 2011). En cambio, se reducen significativamente en la ciudad de Alicante $(5,05 \%)$, donde prevalece la población española $(86,56 \%)$ y se incrementa la presencia de emigrantes por motivos laborales $(13,4 \%)$, procedentes de Sudamérica y Norte de África, dado el predominio de la función de servicios y el menor peso de las actividades turístico-residenciales.

El análisis de las tendencias de consumo de agua (2005-2015) se ha llevado a cabo diferenciando entre tipología urbana y tipo de ocupación del hogar (principal o secundaria). Para la identificación de las tipologías urbanas analizadas se han teniendo en cuenta las categorías identificadas por García (2012) y Morote (2014):

-Viviendas de los núcleos urbanos tradicionales (edificios en bloque y en altura) caracterizadas por la ausencia de elementos exteriores. Para esta tipología sólo se ha tenido en cuenta las viviendas principales.

-Viviendas de bloques de apartamentos con elementos externos, pero donde el consumo de agua del jardín y la piscina no se contempla en estos hogares ya que se contabiliza en contadores comunitarios. Para el caso de Rojales no se ha tenido en cuenta esta tipología urbana debido a su inexistencia en su término municipal.

-Viviendas adosadas que cuentan con un pequeño jardín-patio privado cuyo consumo computa en la factura doméstica y una zona comunitaria (jardín y piscina), cuyo gasto de agua es medido por un contador comunitario y por tanto, no se contabiliza en el consumo del hogar.

- Chalés. Hogares que disponen de jardín y piscina unifamiliar y el gasto de agua, tanto exterior como interior de la vivienda, se registra en un único contador individual.

El grado de ocupación ha sido determinado a partir de la consulta de datos estadísticos (Censo de vivienda) y la realización de trabajo de campo y entrevistas a los gerentes y técnicos de la empresa suministradora de agua (Hidraqua, Gestión Integral de Aguas de Levante S.A). Cabe indicar que los hogares de los núcleos urbanos tradicionales, de manera general, no se ven afectados por la estacionalidad ya que suelen ser viviendas ocupadas durante todo el año. En este sentido, para esta tipología todas las viviendas se han computado como viviendas principales. En el resto de las tipologías, se diferencia entre viviendas principales y secundarias. En el caso de estas últimas cabe tener en cuenta la complejidad a la hora de analizar los datos de la tendencia de consumo, ya que una de las características de estos hogares es la aleatoriedad a la hora de determinar el grado de ocupación entre unos años y otros, dado el amplio número de factores que inciden su uso (distribución de días festivos, periodo vacacionales, estructura de la familia, nivel de ingresos, distancia entre la vivienda principal y la secundaria, etc.). Una última cuestión a tener en cuenta desde el punto de vista del grado de ocupación es la existencia de viviendas vacías, consideradas como tales, aquéllas que presentan un consumo 0 a lo largo de todo el 
año, resultado bien del carácter especulativo del boom inmobiliario o bien de la no ocupación por sus propietarios. El número de contadores con consumo 0 durante algunos meses es una cifra que proporciona un dato esencial para relacionar el gasto de agua y la estacionalidad.

Junto a la vivienda residencial, se han analizado los consumos de agua en hoteles en las ciudades que presentan una planta hotelera significativa (Benidorm y Alicante). A partir del Anuario sobre Oferta Turística Municipal y Comarcal de la Agencia Valenciana de Turismo de 2015, se seleccionaron hoteles representativos de estos municipios teniendo en cuenta su categoría. En su análisis, se ha adoptado la metodología utilizada en publicaciones que han estudiado los consumos hoteleros en la costa de Alicante (Olcina et al., 2016) y en la Costa Brava (Cataluña) (Gabarda et al., 2017).

La información manejada en esta investigación ha sido facilitada por la empresa Hidraqua, Gestión Integral de Aguas de Levante S.A. (integrante del Grupo Aquadom) que suministra agua potable a los municipios objeto de estudio y a la mayor parte de las localidades costeras de la provincia de Alicante. La información a escala local que se ha analizado ha sido la siguiente:

-Volumen anual suministrado y facturado por municipio $\left(\mathrm{hm}^{3}\right)(2005-2015)$

-Volumen suministrado mensual a escala municipal $\left(\mathrm{m}^{3}\right)(2005-2015)$

-Número de contadores y viviendas conectadas a la red por municipio (2005-2015)

-Número de total de lecturas al año de contadores con consumo 0 por municipio (2005-2015)

-Número de contadores de telelectura (Smart Meters) por municipio (2005-2015)

-Longitud de la red de distribución en baja y de la red de saneamiento por municipio (km) (2015)

-Rendimiento de la red de distribución por municipio (\%) (2005-2015)

-Litros/hab/día por municipio (2005-2015)

-Volumen suministrado $\left(\mathrm{m}^{3}\right)$ trimestralmente por tipología de vivienda (núcleo urbano, boques de apartamentos, adosados y chalés) y diferenciando, a su vez, por el tipo de ocupación (principal y secundaria) por municipio (2005-2015)

-Volumen suministrado anual $\left(\mathrm{m}^{3}\right)(2005-2015)$ y mensual (2015) de hoteles en función de la categoría (de 1 a 5 estrellas) para las ciudades de Alicante y Benidorm, y consumo por plaza y día (2005-2015).

En relación con los datos facilitados de las viviendas, fueron los técnicos de la empresa los encargados de seleccionar aquéllos contadores representativos, desechando los que por motivos varios (años en el que la vivienda no ha sido ocupada, errores de medición, etc.), podrían influir en el análisis estadístico y, por tanto, en la tendencia. En total, se escogieron 10 contadores por tipología urbana, diferenciando a su vez entre principal y secundaria y por municipio. Por cada contador se facilitaron 4 facturas anuales (trimestrales) y 3 años $(2005,2010$ y 2015) arrojando finalmente una cifra total de 4.200 datos de facturación entre los 5 municipios. En el caso de los hoteles, fueron seleccionados 5 hoteles por ciudad (Alicante y Benidorm) y número 
de estrellas (de 1 a 5 estrellas), es decir, un total de 50 establecimientos (1.950 datos de facturación).

El manejo de datos de facturación de viviendas atendiendo a la representatividad de cada tipología urbana y el grado de ocupación (principal o secundaria) y un análisis específico del consumo hídrico en la planta hotelera en los municipios seleccionados es un elemento innovador en la metodología utilizada para el análisis de las tendencias del gasto de agua en el litoral mediterráneo español. Debido a la dificultad y complejidad para acceder a datos reales de consumo de agua en España, esta investigación supone un avance importante en el conocimiento de la tendencia del gasto de agua en esta parte de la Europa Mediterránea, ya que se ha basado en datos reales de suministro y de facturación y no en estimaciones de demanda realizadas desde diferentes organismos nacionales (INE, AEAS, etc.). El análisis de datos empíricos reales permite profundizar en las relaciones que se establecen entre tipologías urbanas y características socio-económicas de sus habitantes, así como en los factores coyunturales y estructurales que pueden incidir en el gasto de agua urbano-turístico.

\section{Resultados}

\subsection{Una tendencia general de disminución del consumo de agua influida por factores estructurales y coyunturales}

Desde mediados de la primera década del 2000, el descenso del consumo de agua potable se ha generalizado en toda España y en el resto de aglomeraciones urbanas de los países desarrollados (Gil et al., 2015). Esta tendencia se observa en el área de estudio en todos los municipios y tipologías urbanas, donde la reducción oscila entre el $15 \%$ (Torrevieja) y el 30\% (L'Alfàs del Pi). Ante estos datos, cabría esperar un descenso o estabilización del número de usuarios conectados a la red, hecho que no se ha producido, sino que, al contrario, se ha incrementado; variando este porcentaje entre el $8,5 \%$ en Torrevieja y el $36,6 \%$ en Benidorm (Tabla 1 ).

Teniendo en cuenta que se ha producido un aumento de los usuarios conectados a la red desde 2005, los factores que explican la tendencia decreciente del consumo se asocian a su función socio-económica (turística-residencial) y a la adopción de estrategias encaminadas a la contención del gasto, que varían dependiendo de la tipología urbana mayoritaria. A estos factores, hay que unir el efecto de la crisis económica que se inició en 2008 ya que, como se ha constatado empíricamente, este descenso se ha producido de manera muy intensa hasta el año 2010 y se prolonga hasta el 2013 de manera más contenida. 
Tabla 1. Evolución de los consumos, contadores y rendimiento de la red de distribución de agua potable (2005-2015)

\begin{tabular}{|c|c|c|c|c|}
\hline & & 2005 & 2010 & 2015 \\
\hline \multirow[t]{5}{*}{ L'Alfàs del Pi } & Volumen suministrado $\left(\mathrm{m}^{3}\right)$ & 3.073 .983 & 2.748 .133 & 2.245 .477 \\
\hline & Contadores totales $\left(n^{0}\right)$ & 11.113 & 12.219 & 13.082 \\
\hline & Contadores de telelectura $\left(n^{0}\right)$ & 0 & 0 & 226 \\
\hline & $\begin{array}{l}\text { Número total de lecturas al } \\
\text { año con consumo } 0\end{array}$ & 5.262 & 3.665 & 3.347 \\
\hline & Rendimiento de la red (\%) & 67,00 & 67,10 & 80,70 \\
\hline \multirow[t]{5}{*}{ Alicante } & Volumen suministrado $\left(\mathrm{m}^{3}\right)$ & 29.652 .780 & 24.006 .089 & 22.241 .133 \\
\hline & Contadores totales $\left(n^{0}\right)$ & 182.869 & 194.616 & 202.091 \\
\hline & Contadores de telelectura $\left(n^{0}\right)$ & 0 & 0 & 84.247 \\
\hline & $\begin{array}{l}\text { Número total de lecturas al } \\
\text { año con consumo } 0\end{array}$ & 27.288 & 39.417 & 29.430 \\
\hline & Rendimiento de la red (\%) & 83,62 & 90,73 & 90,43 \\
\hline \multirow[t]{5}{*}{ Benidorm } & Volumen suministrado $\left(\mathrm{m}^{3}\right)$ & 12.425 .959 & 10.022 .550 & 10.110 .242 \\
\hline & Contadores totales $\left(\mathbf{n}^{\circ}\right)$ & 15.833 & 19.300 & 21.581 \\
\hline & Contadores de telelectura $\left(n^{0}\right)$ & 0 & 0 & 1.466 \\
\hline & $\begin{array}{l}\text { Número de lecturas anuales de } \\
\text { contadores con consumo } 0\end{array}$ & 3.769 & 7.539 & 1.665 \\
\hline & Rendimiento de la red (\%) & 90,52 & 93,90 & 95,03 \\
\hline \multirow[t]{5}{*}{ Rojales } & Volumen suministrado $\left(\mathrm{m}^{3}\right)$ & 2.054 .658 & 1.722 .433 & 1.788 .396 \\
\hline & Contadores totales $\left(\mathrm{n}^{0}\right)$ & 12.222 & 14.442 & 14.970 \\
\hline & Contadores de telelectura $\left(n^{0}\right)$ & 0 & 0 & 1.466 \\
\hline & $\begin{array}{l}\text { Número de lecturas anuales de } \\
\text { contadores con consumo } 0\end{array}$ & 2.982 & 6.264 & 5.513 \\
\hline & Rendimiento de la red (\%) & 79,07 & 83,11 & 83,28 \\
\hline \multirow[t]{5}{*}{ Torrevieja } & Volumen suministrado $\left(\mathrm{m}^{3}\right)$ & 9.966 .560 & 8.658 .750 & 8.509 .609 \\
\hline & Contadores totales $\left(n^{0}\right)$ & 111.996 & 120.284 & 121.516 \\
\hline & Contadores de telelectura $\left(\mathrm{n}^{\circ}\right)$ & 0 & 0 & 1.775 \\
\hline & $\begin{array}{l}\text { Número de lecturas anuales de } \\
\text { contadores con consumo } 0\end{array}$ & 71.406 & 96.350 & 103.775 \\
\hline & Rendimiento de la red (\%) & 92,87 & 92,77 & 87,96 \\
\hline
\end{tabular}

Fuente: Hidraqua, Gestión Integral de Aguas de Levante, S.A. Elaboración propia.

La crisis económica ha afectado principalmente a localidades costeras caracterizadas por la función residencial y ha provocado un descenso en la afluencia de residentes estacionales y de la duración de la ocupación de segundas residencias, tanto en época estival como en otros periodos vacacionales, determinando incluso que muchas viviendas no se ocupen a lo largo del año. Las localidades turísticoresidenciales, a diferencia de la ciudad de Alicante, se identifican por un porcentaje de vivienda secundaria que supera el $50 \%$ (duplicando la media provincial que se sitúa en el 26,9\%) (INE, 2011). El número de contadores con consumo 0 relaciona el 
gasto de agua y la estacionalidad. Paradigmática es, por ejemplo, la ciudad de Torrevieja, donde se registran de media entre 38.000-40.000 contadores domésticos con consumo 0 en todos los trimestres, pero es a partir del año 2012 cuando esta cifra se ha incrementado hasta situarse en torno a los 50.000 contadores sobre un total de $121.182(41,26 \%)$. Según los datos ofrecidos del número de lecturas anuales de contadores con consumo 0 , se observa como en todas las localidades analizadas (salvo en Torrevieja), su número ha descendido entre 2010 y 2015, lo que indica que en ese primer año, las viviendas secundarias tuvieron una menor ocupación debido principalmente a la crisis económica (Tabla 1).

Tabla 2. Contadores/Km de red y viviendas/ $\mathrm{Km}$ red $(2015)^{5}$

\begin{tabular}{|l|r|r|}
\hline & Contadores/Km de red & Viviendas/Km de red \\
\hline L'Alfàs del Pi & 76,70 & 72,74 \\
\hline Alicante & 179,50 & 165,67 \\
\hline Benidorm & $88,24^{*}$ & 237,20 \\
\hline Rojales & 58,85 & 56,08 \\
\hline Torrevieja & 177,37 & 178,55 \\
\hline
\end{tabular}

Fuente: Hidraqua, Gestión Integral de Aguas de Levante, S.A. Elaboración propia.

El descenso generalizado desde mediados de la década del 2000 no sólo se puede relacionar con la crisis económica, sino también con factores socio-demográficos (pérdida de población) y las condiciones climáticas (episodios de sequía). En segundo lugar, también han sido decisivos diferentes factores estructurales como son las medidas adoptadas tanto por los usuarios finales (instalación de dispositivos de ahorro, nuevos electrodomésticos más eficientes en el consumo de agua, incremento de la percepción ambiental a favor del ahorro de agua, etc.) en viviendas nuevas, pero también en otras ya construidas, a medida que se acometían reformas e igualmente en comercios, industrias y edificios públicos. Otro de los factores que más ha repercutido en la reducción del volumen suministrado ha sido la mejora en el rendimiento de la red de abastecimiento y las innovaciones en materia de detección de fugas y fraude como es el caso de la implementación de la telelectura (March et al., 2017). Por ejemplo, los porcentajes de eficiencia en los años ochenta y noventa, en la mayoría de los casos se situaban por debajo del $70 \%$, mientras que en la actualidad se sitúan por encima de estos valores: l'Alfàs del Pi $(80,70 \%)$, Alicante $(90,43 \%)$, Benidorm $(95,03 \%)$, Rojales $(83,28 \%)$ y Torrevieja $(87,97 \%)$ (Tabla 1$)$.

\footnotetext{
${ }^{5}$ Nota: Para el caso de las viviendas se ha tomado como referencia el Censo de viviendas de 2011. Para el caso de la ciudad de Benidorm cabe tener en cuenta que hasta 1995 prácticamente la totalidad de los contadores era comunitarios (por bloque y no individuales por vivienda) y aún en la actualidad son los predominantes. A partir de 1995 se fomentó la instalación de contadores individuales, tanto en las nuevas construcciones como en nuevos contratos.
} 
Otra cuestión clave a considerar en el análisis de los datos de consumo es su relación con las tipologías urbanas existentes. El gasto de agua en zonas urbanas de alta densidad y de estructura vertical es manifiestamente inferior al de zonas urbanas de baja densidad, si bien, siempre en módulos personales de gasto, ya que en estos últimos hay presencia de usos exteriores (jardines y piscinas), que en ocasiones pueden llegar a representar hasta la mitad o más del consumo total doméstico de una vivienda. La ciudad compacta permite, además, una gestión más eficiente del ciclo integral del agua. Una mayor longitud de las redes de distribución, asociado a modelos urbanos extensivos, conlleva un aumento de las pérdidas en la red en litros $/ \mathrm{km} /$ día y del volumen de agua no registrada (ANR) y además se eleva la complejidad y dificultad en la detección de fugas (Rico, 2007). En este sentido, se puede observar como en los modelos urbanos extensivos se incrementa el número de $\mathrm{km}$ de red (Torrevieja) y se reduce en el modelo urbano compacto (Benidorm). Todo ello hace que el índice de contadores por $\mathrm{km}$ de red se reduzca en las tipologías extensivas frente a las más concentradas: l'Alfàs del Pi (76,70 contadores/km de red) frente a los 179,50 de Alicante (Tabla 2).

\subsection{La evolución del consumo de agua en viviendas urbano-turísticas. Una tendencia influida por las tipologías urbanas y la ocupación estacional}

La tendencia del gasto de agua facturada por vivienda en el intervalo de 2005 a 2015 y su adscripción en función de las diferentes tipologías urbanas y el tipo de ocupación queda recogida en la Tabla 3. De manera general, la mayoría de las tipologías registran una tendencia decreciente, si bien, este porcentaje varía en función de la localidad, de la tipología urbana y del tipo de ocupación. En los núcleos urbanos (Figura 2), la tendencia ha sido decreciente con porcentajes que varían desde un $40 \%$ (Torrevieja) hasta un $26 \%$ en l'Alfàs del Pi. Este descenso ha sido continuado desde 2005 , sin haber ningún síntoma de recuperación en ningún año.

En viviendas principales en bloques de apartamentos (Figura 3), el gasto de agua ha sido negativo salvo el caso de Benidorm que desde 2005 ha registrado un incremento del 18\%, pasando de 315 1/viv/día a 372 1/viv/día. Ello se debe al modelo de ciudad turística con gran dinamismo en actividades de ocio y servicios, lo que ha evitado los efectos de la crisis económica. Es de notar que en 2015 se batieron records en este sector económico: la provincia de Alicante alcanzó la cifra de 5,9 millones de pernoctaciones en apartamentos concentrando Benidorm el $41 \%$ de la provincia (Agencia Valenciana de Turismo, 2015). 
Tabla 3. Tendencia del consumo de agua urbano-turística por tipología urbana y ocupación de la vivienda (\%) $(2005-2015)^{6}$

\begin{tabular}{|l|r|r|r|r|r|r|r|}
\hline & Núcl. urbano tradicional & \multicolumn{2}{|c|}{ Apartamentos } & \multicolumn{2}{|c|}{ Adosados } & \multicolumn{2}{c|}{ Chalés } \\
\cline { 2 - 8 } & Principal & Principal & Secundaria & Principal & Secundaria & Principal & Secundaria \\
\hline L'Alfàs del Pi & -26 & -18 & -27 & -20 & -69 & -18 & 19 \\
\hline Alicante & -32 & -16 & -56 & -19 & -48 & -20 & -1 \\
\hline Benidorm & -40 & 18 & -5 & -22 & -20 & -21 & -50 \\
\hline Rojales & -28 & - & - & -22 & -22 & 7 & -26 \\
\hline Torrevieja & -39 & -12 & 3 & -22 & 9 & 19 & -29 \\
\hline
\end{tabular}

Fuente: Hidraqua, Gestión Integral de Aguas de Levante, S.A. Elaboración propia.

Figura 2. Tendencia del consumo de agua en viviendas del núcleo urbano tradicional (viviendas principales) (2005-2015).

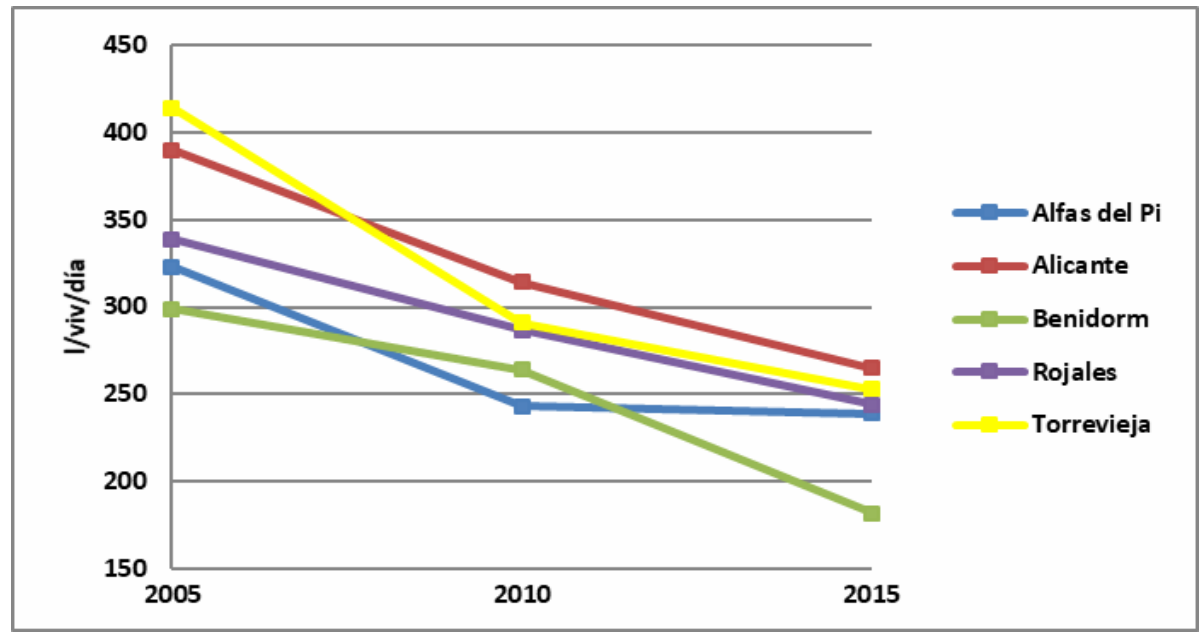

Fuente: Hidraqua, Gestión Integral de Aguas de Levante S.A. Elaboración propia.

Para el caso de las viviendas secundarias, la tendencia ha sido igualmente regresiva, destacando el descenso de un 56\% para la ciudad de Alicante, excepto Torrevieja, donde se registra un leve incremento del 3\%. Uno de los rasgos particulares de las viviendas secundarias es la casuística diversa que puede determinar el comportamiento anual del consumo ya que un mismo hogar puede tener un alto

\footnotetext{
${ }^{6}$ En color verde se han representado las tipologías donde se ha incrementado el consumo y en rojo las que han descendido. El color blanco significa que no existe esa tipología urbana en la localidad.
} 
grado de ocupación un año y, sin embargo, en otro, no haber sido ocupado. Ello puede explicar el descenso para el caso de Alicante donde la crisis económica ha mermado el número de viviendas ocupadas y ha acortado la duración de la estancia (especialmente entre los años 2010-2013). En cambio, en Benidorm, localidad con mayor peso de las actividades turísticas, se ha producido un ligero incremento de la ocupación desde 2010, si bien sin alcanzar el consumo por habitante y día de 2005.

Figura 3. Tendencia del consumo de agua en viviendas de bloques de apartamentos. Viviendas principales (imagen superior) y viviendas secundarias (imagen inferior) (2005-2015) ${ }^{7}$

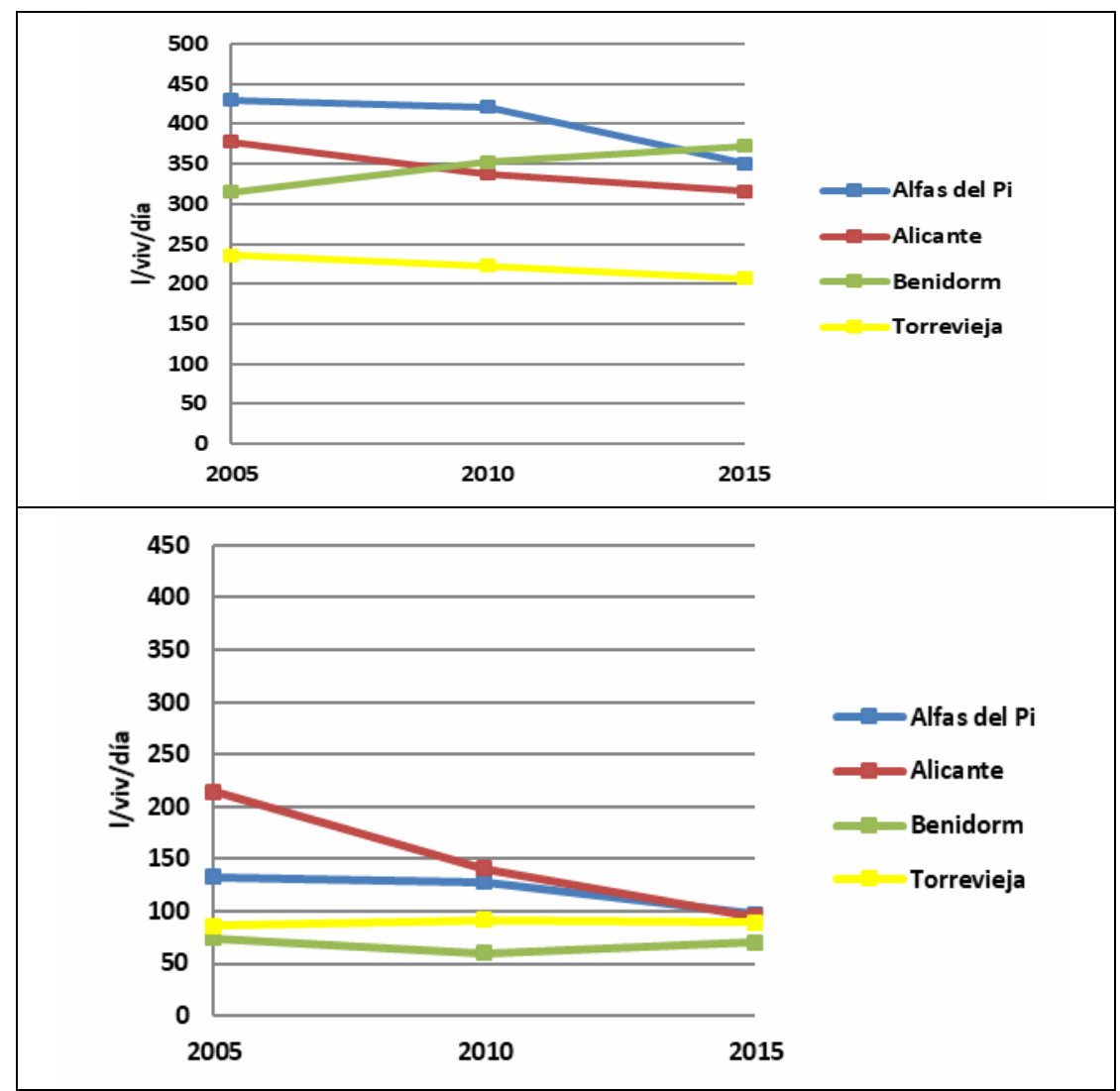

Fuente: Hidraqua, Gestión Integral de Aguas de Levante S.A. Elaboración propia.

Las viviendas adosadas (Figura 4) se caracterizan por tener jardín y piscina comunitaria, un pequeño jardín-patio privado y por ser ocupadas por familias jóvenes y con niños (Morote et al., 2016). La literatura científica refleja que en las viviendas

${ }^{7}$ Nota: En Rojales no existe la tipología urbana de bloques de apartamentos. 
donde reside población joven y con niños, el consumo medio de agua es mayor que en aquéllas donde residen personas mayores (Troy et al., 2005). En las viviendas principales, todos los municipios muestran una tendencia regresiva con valores medios en torno al $20 \%$. En las viviendas secundarias, la caída del consumo es también mayoritaria y muy destacada en las ciudades de l'Alfàs del Pi y Alicante, con una aminoración del 69 y 48\%, respectivamente. No obstante, cabe señalar que se ha producido un ligero incremento a partir del año 2010 para el caso de Rojales y Torrevieja pasando de 78 a 111 1/viv/día y 56 a 71 1/viv/día, respectivamente. En secundarias, de manera general, a partir de 2010 se observa una aminoración en la intensidad del proceso de reducción de los consumos e incluso, en ciudades como Benidorm o Rojales (de clara filiación turístico-residencial) se registra una tendencia alcista, pero sin alcanzar los valores de partida en 2005.

Figura 4. Tendencia del consumo de agua en viviendas adosadas. Viviendas principales (imagen superior) y viviendas secundarias (imagen inferior) (2005-2015)

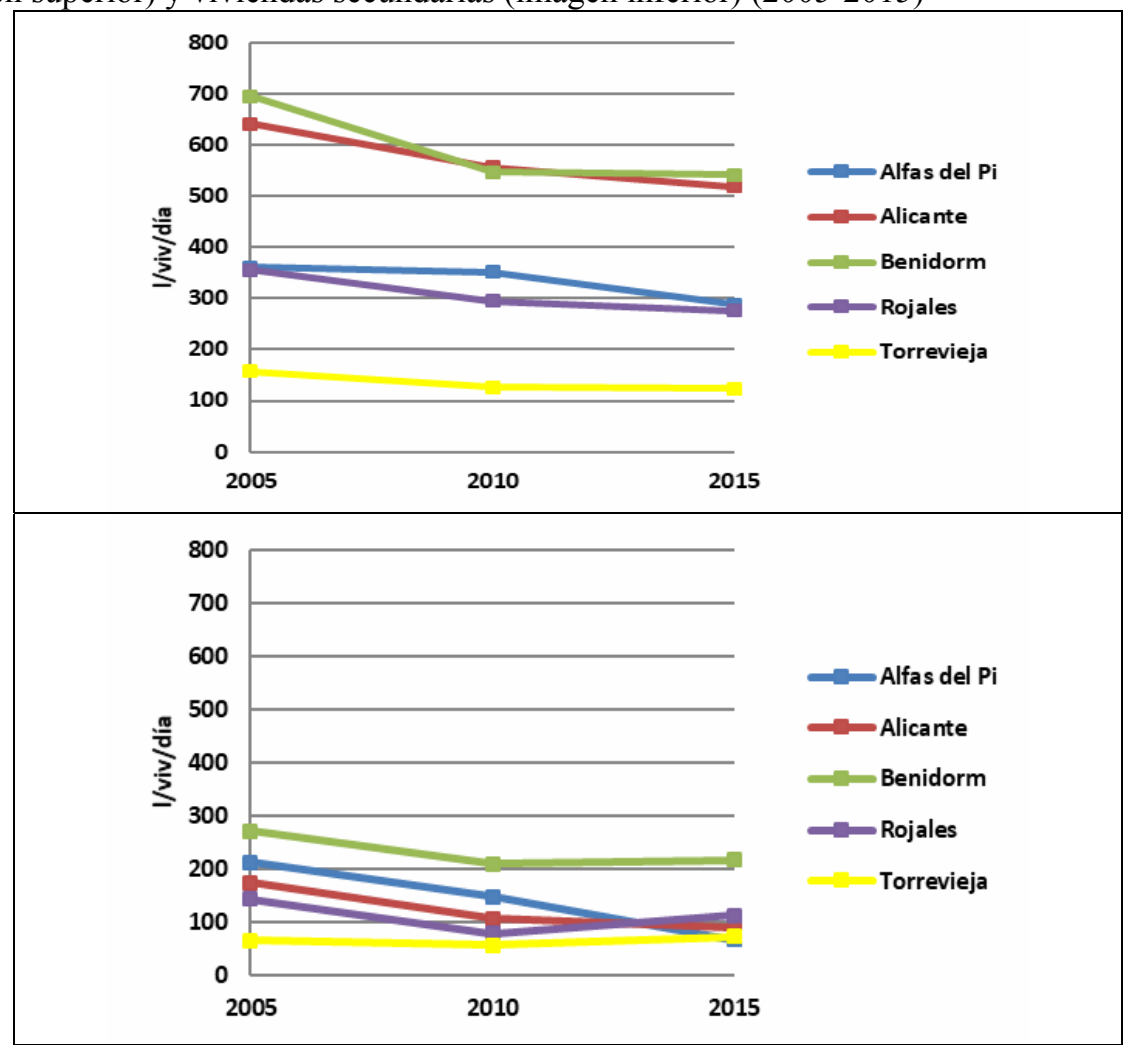

Fuente: Hidraqua, Gestión Integral de Aguas de Levante S.A. Elaboración propia.

En las viviendas de chalés (Figura 5), al haber una presencia de usos exteriores, los consumos se elevan considerablemente, tanto en viviendas principales, oscilando 
en 2015 entre los 1.475 1/día de Alicante y los 655 1/día de Rojales, y en secundarias, entre los 457 1/día de Torrevieja y los 208 1/día de Benidorm. La evolución de los consumos en vivienda principal pone de manifiesto una evolución dual. Frente a municipios como Alicante o Benidorm que han reducido significativamente los consumos, las localidades de Rojales y Torrevieja han experimentado un incremento del 7 y 19\%, respectivamente. En viviendas secundarias, la disminución de los consumos es la tendencia dominante en todos los municipios, con la excepción de l'Alfàs del Pi. En Rojales y Torrevieja, el porcentaje de reducción ha sido del $26 \mathrm{y}$ $29 \%$, respectivamente entre 2005-2015. No obstante, cabe señalar que desde 2010 se ha producido un aumento al pasar de 231 a 338 1/viv/día y de 411 a 457 1/viv/día, respectivamente. A pesar de ello, estos valores están notablemente por debajo de los registrados en 2005.

Figura 5. Tendencia del consumo de agua en chalés. Viviendas principales (imagen superior) y viviendas secundarias (imagen inferior) (2005-2015)

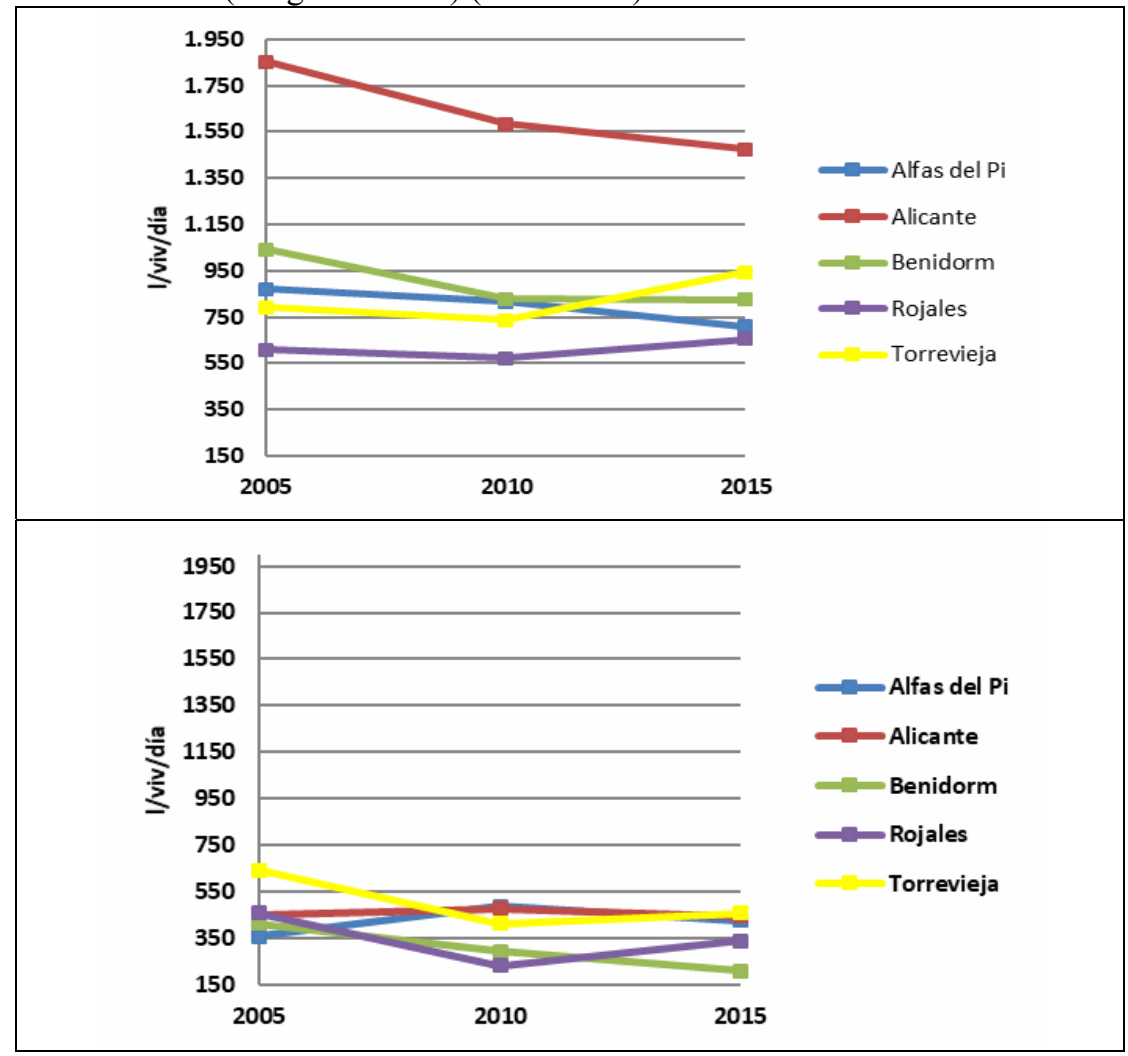

Fuente: Hidraqua, Gestión Integral de Aguas de Levante S.A. Elaboración propia.

Teniendo en cuenta los datos de consumo absolutos, las mayores reducciones se encuentran en la tipología urbana de chalés, en algunos casos, con aminoraciones 
cercanas a 400 1/viv/día como sucede en la ciudad de Alicante en viviendas principales pasando de 1.853 en 2005 a 1.475 1/viv/día en 2015 (un retroceso del $20 \%$ ). Esta dinámica se vincula fundamentalmente a tres factores:

1.Al cambio y mejora de los usos del agua en el exterior de la vivienda. Se han instalado dispositivos de ahorro, sistemas de riego más eficientes y la sustitución de vegetación atlántica por mediterránea en los jardines y la conservación del agua de la piscina durante varios años (Morote y Hernández, 2016a).

2.El incremento de la factura del agua (alrededor de un 77\% en tan sólo una década) como ha sucedido en la ciudad de Alicante (Gil et al., 2015). Este aumento ha tenido una gran influencia en esta tipología dada la presencia de usos exteriores y la aplicación de tarifas progresivas por tramos que penalizan los consumos elevados.

3.El uso y sustitución de agua potable por recursos alternativos (aguas regeneradas depuradas y pluviales) para su empleo en el exterior del hogar de manera creciente en algunas localidades. Paradigmática es la ciudad de Alicante, donde la utilización de aguas regeneradas depuradas inyectadas a la red de distribución para el riego tanto de jardines privados como parques y jardines públicos ha permitido la reducción de $1 \mathrm{hm}^{3}$ de agua potable (Morote y Hernández, 2017).

\subsection{La evolución del consumo de agua en establecimientos hoteleros. Una tendencia influida por la categoría y el comportamiento de la actividad turística}

El análisis de los datos de facturación de agua potable suministrada a establecimientos hoteleros en distintas categorías para los casos de las ciudades de Alicante y Benidorm evidencia diferentes tendencias en función del municipio y número de estrellas del hotel. De manera general, el gasto depende de diferentes componentes como son el tamaño y la complejidad de las instalaciones del establecimiento, el tipo de servicios que se ofertan, las condiciones climáticas, los sistemas de irrigación utilizados y la incorporación de políticas de gestión y ahorro del agua.

Benidorm se ha configurado como uno de los principales destinos turísticos del Mediterráneo español. Esta auténtica ciudad del ocio presenta unas características únicas en cuanto a su configuración como destino turístico, en el papel que juega su jerarquía urbana y en la capacidad de influir y organizar el entorno comarcal (Rico et al., 2009). Desde mediados del pasado siglo XX, el turismo y los servicios vinculados son el motor de las dinámicas sociales, económicas y demográficas de la ciudad. Se trata de un destino basado en el producto de "Sol y Playa", gracias a sus más de cinco kilómetros de playas urbanas en exposición meridional y a unos condicionantes climáticos muy favorables (Olcina y Miró, 2016). Cuenta con una potente planta de alojamiento reglado con una fuerte especialización hotelera (el $32 \%$ del total de las plazas de la Comunidad Valenciana) especialmente en categorías medias (50,9\% en 3 estrellas) y medias-altas (36\% en 4 estrellas) (IVE, 2015). Es la cuarta ciudad de España en cuanto a la planta de alojamiento hotelero (128 hoteles y 40.087 plazas), el 
segundo destino de sol y playa tras Calvià (Islas Baleares), pero con una marcada diferencia ya que mientras Benidorm mantiene activa más del $80 \%$ de esa planta de alojamiento durante todo el año, en el caso del destino balear ese indicador desciende hasta el $10 \%$. Los datos del comportamiento de la actividad turística reflejan la importancia de este sector en esta ciudad. Por ejemplo, en 2015, la provincia de Alicante recibió 4,7 millones de turistas extranjeros, que realizaron un total de 52,2 millones de pernoctaciones, concentrando Benidorm el 21\% de los turistas (Agencia Valenciana de Turismo, 2015). En el caso de Alicante, el número total de hoteles asciende a 35 (6.646 plazas) (IVE, 2015). A diferencia de Benidorm, su condición de capital provincial determina el predominio de las actividades comerciales y de servicios. El sector turístico (cultural y de sol y playa) se localiza en el centro de la ciudad y en el sector de la Playa de San Juan, Cabo de la Huerta y La Albufereta, distritos caracterizados por la presencia de apartamentos y segundas residencias de población española.

En Benidorm, en relación con los consumos hoteleros, se han identificado dos tendencias (Tabla 4). Por una parte, los establecimientos que han reducido su consumo (hoteles de 3 y 1 estrella), mientras que los de 5, 4 y 2 estrellas han aumentado el gasto de agua. De todos ellos, los que más agua consumen son los de 4 estrellas con una media de $120.613 \mathrm{~m}^{3}$ /año (incremento del 4,27\%), mientras que si se relaciona por el número de plazas, los que tienen más gasto de agua son los de 5 estrellas (520 litros/plaza/día) con un incremento del 35,57\%. Por otro lado, los que menos agua consumen son los de 1 estrella $\left(7.344 \mathrm{~m}^{3} /\right.$ año y 287 litros/plaza/día) con una reducción del 39\% desde 2005. Para el caso de la ciudad de Alicante se observa como la tendencia desde 2005 ha sido positiva para los hoteles de 5 estrellas $(+32 \%)$, 4 estrellas $(+12,44 \%)$ y 3 estrellas $(+23,17 \%)$. En relación con los que han visto reducido su consumo se encuentran los de 2 estrellas y 1 estrella (reducción del $34,52 \%$ y $9,14 \%$ respectivamente). Los que mayor gasto de agua registran son los hoteles de 4 estrellas $\left(13.416 \mathrm{~m}^{3} /\right.$ año) mientras que por plaza, destaca el consumo de agua en los de 5 estrellas (338 litros/plaza/día) y los de menos gasto, los establecimientos de 1 estrella $\left(1.570 \mathrm{~m}^{3} /\right.$ año y 143 litros/plaza/día).

De los datos anteriores se observa semejanzas y diferencias entre las dos ciudades con funciones económicas contrastadas. Entre las primeras, cabe mencionar que los mayores consumos se dan en aquellos establecimientos hoteleros de mayor calidad (5 y 4 estrellas) que destacan por tener multitud de elementos que consumen agua como un mayor número de piscinas, espacios ajardinados, mayor número de plazas, mayor número de dispositivos que usan agua dentro de las habitaciones, etc., y porque este tipo de hoteles suele incorporar actividades vinculadas con el wellness. Sin embargo, cabría pensar que es en estos establecimientos de mayor calidad donde mayor es también la eficiencia por plaza hotelera, bien por externalizar algunos servicios (por ejemplo, lavandería) o bien, por la adopción de sistemas de ahorro de agua tanto en los usos exteriores como interiores. Se trata de una relación ya establecida por autores como Bohdanowicz y Martinac (2007), Erdogan y Baris (2007), Gabarda et al., (2017) y Olcina et al., (2016). Pero, como se ha podido comprobar, es justo en los hoteles de 5 y 4 estrellas donde mayores son los consumos por plaza y día, tanto para la ciudad 
de Alicante como Benidorm. También cabe indicar la notable diferencia entre los hoteles que más agua consumen entre estas dos ciudades. Por ejemplo, en los hoteles de Benidorm (4 estrellas) se consume de media al año $120.613 \mathrm{~m}^{3}$ mientras que para los que más consumen en Alicante el gasto de agua alcanza la cifra de $13.416 \mathrm{~m}^{3}$ (también para los de 4 estrellas). Es un contraste que se puede observar en todas las categorías de hoteles entre estas dos ciudades, es decir, un mayor consumo de agua a favor de los de la ciudad de Benidorm.

Tabla 4. Tendencia comparada del consumo de agua en hoteles de Alicante y Benidorm según el número de estrellas, 2005-2015 $\left(\mathrm{m}^{3}\right)$

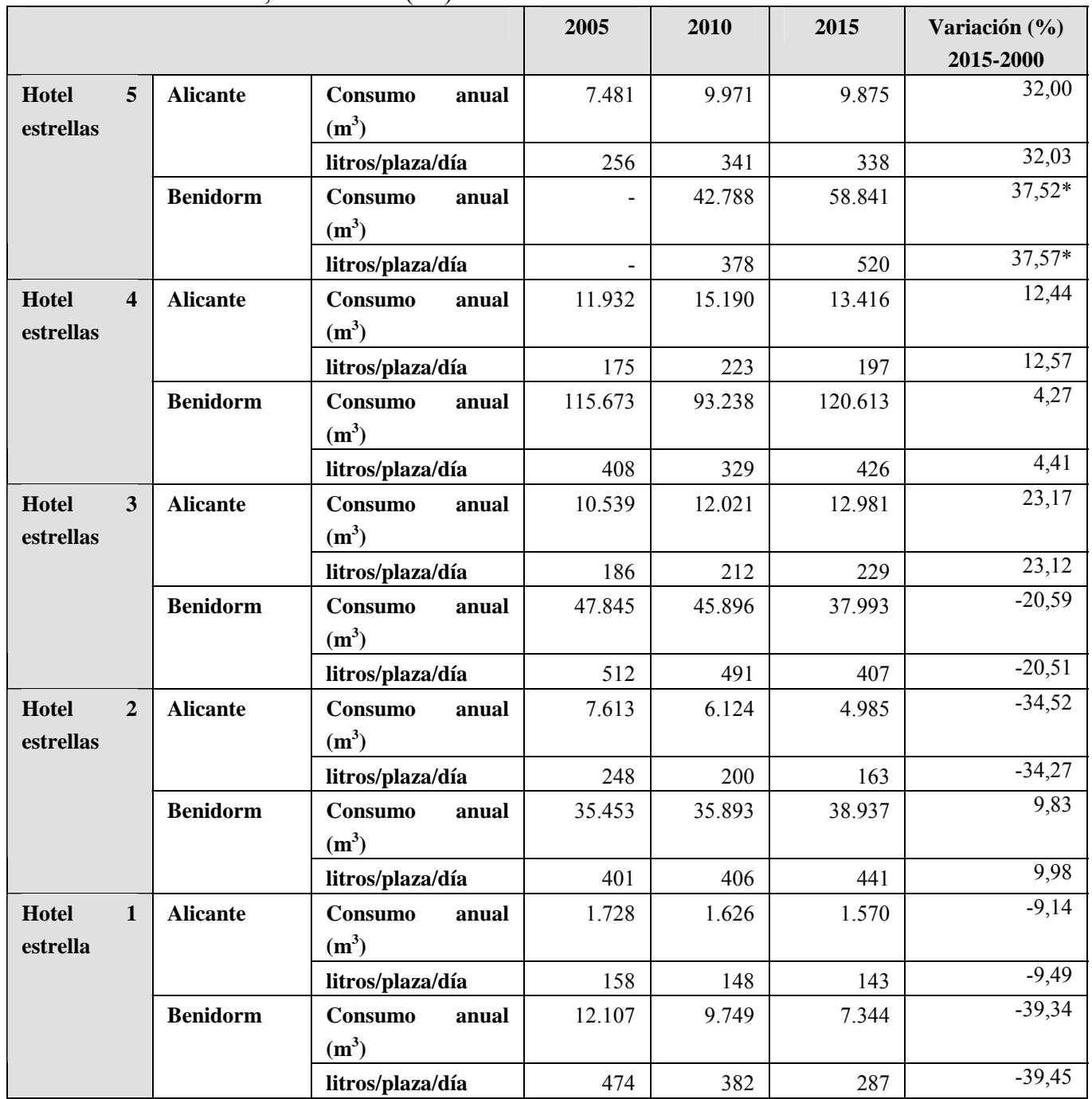

Fuente: Hidraqua, Gestión Integral de Aguas de Levante S.A. Elaboración propia. 
Las diferencias se relacionan con la función económica de la ciudad en la que ésta se encuentra. Ello obedece tanto a la mayor superficie de espacios externos que consumen agua (jardines y piscinas), número de plazas y ocupación hotelera a lo largo del año. En Alicante, su carácter de ciudad de servicios determina que el mayor consumo de agua por plaza y día se registre en los hoteles de 5 estrellas. El efecto de la crisis económica en la función productiva (que ha incidido con mayor intensidad que en Benidorm) se ha traducido en que sean los establecimientos de media calidad ( 3 y 2 estrellas e incluso los de 1 estrella), donde el gasto de agua por plaza y día se haya reducido fruto de los dispositivos de ahorro instalados durante los últimos años con el objetivo de aminorar el consumo y precio pagado de la factura del agua. Todo ello hay que relacionarlo con los efectos de la crisis económica y el incremento del precio del agua que para el caso de Alicante, ha aumentado un $77 \%$ en la última década (Gil et al., 2015).

\section{Discución y conclusiones}

Las causas del incremento del consumo de agua potable en el litoral de Alicante hasta mediados de la década del 2000 son diversas, pero un factor de primer orden fue la expansión de nuevas áreas de uso residencial y turístico y, asociado a éste, el fuerte dinamismo económico que registró este territorio desde los años sesenta y mediados de los años noventa del pasado siglo hasta la crisis financiera de 2008. Durante la pasada década, se generalizó la percepción de que un incremento del número de viviendas, $\mathrm{y}$, por tanto, de usuarios conectados a la red, iría asociado a un aumento del gasto de agua. Sin embargo, esa impresión generalizada tiene excepciones. Por ejemplo, Del Moral (1998), para el caso de estudio de Sevilla, puso de manifiesto una tendencia decreciente desde el final de la sequía de 1992-95 y que las proyecciones de crecimiento de la demanda a veinte años (1992-2012) llevadas a cabo por la empresa encargada del suministro de agua y la Confederación Hidrográfica del Guadalquivir estaban infundadas. En contraposición al caso andaluz, en el sureste peninsular y más concretamente en la provincia de Alicante, la sequía de 1992-95, a pesar de que sí significó una reducción considerable del gasto de agua, especialmente por las restricciones y una percepción de la población de escasez de agua y una mayor sensibilidad en relación con el gasto hídrico, se trató de una disminución coyuntural ya que posteriormente la demanda de agua volvió a incrementarse (Gil et al., 2015).

Esa percepción de incremento del consumo de agua durante los años del boom inmobiliario, sin embargo, ha sido distinta, ya que ha coincidido con un descenso en la mayor parte de las grandes aglomeraciones urbanas de los países desarrollados (March y Saurí, 2016). Esta tendencia se explica por la combinación de distintos factores de orden tanto estructural como coyuntural. Entre los primeros cabe citar: a) una mayor concienciación ciudadana en torno al ahorro de agua; b) tecnologías más eficientes en uso del agua como las aplicadas en grifería, inodoros, duchas y electrodomésticos; c) uso de recursos hídricos alternativos (aguas regeneradas 
depuradas y pluviales); d) incremento del precio del agua; y e) las mejoras y medidas adoptadas por las empresas suministradoras de agua que han reducido los volúmenes suministrados gracias a la reducción de pérdidas. La eficiencia de estas medidas a medio y a largo plazo difiere. Así, la concienciación y la educación para la conservación del agua son medidas destacadas, pero con efectos a largo plazo pues todos los cambios voluntarios en el comportamiento de los usuarios no son inmediatos. Por el contrario, las modificación en la estructura tarifaria (Sánchez Blanco, 2012) o la mejora de los contadores son más inmediatas (Castillo-Manzano et al., 2013). La incidencia de estas medidas en la tendencia del consumo de agua ha sido analizada, por ejemplo, en la ciudad de Sevilla (Del Moral-Ituarte y Giansante, 2000) o en la de Madrid (Cubillo et al., 2008).

Entre los factores coyunturales, cabe mencionar los últimos episodios de sequía (la de 2005-2004 y la actual desde 2014), cambios sociales y demográficos (pérdida de población) o los efectos de la crisis financiera de 2008 y los procesos de reestructuración de las economías urbanas que han incido sobre el consumo doméstico, industrial y comercial de agua (Gil et al., 2015). En este sentido, en un estudio llevado a cabo por Deoreo y Mayer (2012) en EE.UU. sobre los usos interiores en viviendas unifamiliares se llegó a la conclusión de que el consumo de agua había descendido desde 1995 y además se preveía que esa tendencia continuaría conforme las nuevas tecnologías de ahorro se fueran difundiendo. Por tanto, la combinación de factores estructurales y coyunturales se ha plasmado en la imparable progresión de nuevos hábitos personales y sociales en el gasto de agua potable, que han reducido significativamente los módulos de consumo en litros/hab/día (March y Saurí, 2016; Lute et al., 2015).

La disminución de los consumos conduce hacia una tensión inevitable que se produce entre la tendencia decreciente de los consumos unitarios facturados y la lógica de operación de unas empresas (privadas o mixtas) que quieren mantener su facturación que, en parte, depende de la tendencia de dichos volúmenes facturados. Esta tensión era ya vaticinada a principios del siglo XXI por Del Moral y Giansante (2000). En esta línea, es necesario poner de manifiesto que estas empresas llevan a cabo una importante labor de marketing con las campañas ambientales y de concienciación de ahorro de agua entre la población que, a la postre, significan una reducción del gasto de agua y por ende, de su facturación. A ello se podría añadir que el aumento del precio del agua (un 77\% entre 2007-2013 en la ciudad de Alicante, por ejemplo) (Gil et al., 2015), con lo que se podría compensar ese "desajuste" entre reducción del gasto de agua y facturación. Por tanto, el factor precio del agua es una herramienta muy a tener en cuenta a la hora de la regulación del consumo (ver Sánchez y Blanco, 2012).

El análisis de tendencias de consumo de agua para usos urbano-turísticos en función del municipio, de la tipología urbana y el tipo de ocupación de la vivienda pone de manifiesto que, de manera general, se ha producido un descenso siguiendo la tendencia del volumen total suministrado a la red en baja, si bien, el porcentaje de reducción puede variar en función de las características socio-económicas del municipio. Las mayores reducciones se han producido en Alicante, dado el mayor 
impacto de la crisis económica y el menor peso de las actividades turísticoresidenciales que ponen de manifiesto una recuperación de la dinámica económica e indirectamente, de los consumos de agua como refleja el aumento de turistas y pernoctaciones en la ciudad de Benidorm. A ello, hay que sumar la casuística tan diversa que puede encontrarse en las segundas residencias, ya que se trata de un factor complejo a la hora de explicar la tendencia del gasto de agua.

A escala municipal, los volúmenes suministrados siguen siendo menores que los registrados en 2005, sin embargo, desde 2013 se ha producido una estabilización y un ligero repunte de los consumos totales como ha sucedido en l'Alfàs del Pi, Benidorm, Rojales y en Torrevieja (Morote, 2016b). Ello se debe al buen comportamiento de la actividad turística en 2015 y 2016, que ha registrado record en ocupación hotelera y llegada de visitantes. La provincia de Alicante ha reforzado la posición de la franja litoral como un destino "refugio" en Europa debido a la inestabilidad social y política que ha hundido mercados rivales en el segmento del turismo de "Sol y Playa" como Turquía o Túnez. Por ejemplo, la actividad turística registrada en la comarca de la Marina Baja, donde se sitúa la ciudad de Benidorm, durante el verano de 2016 ha provocado un incremento en la demanda de agua de cerca de un $4,96 \%$ con respecto al mismo periodo de 2015.

En relación con las tipologías urbanas caracterizadas por la presencia de elementos externos como son los jardines y piscinas, éstas han visto reducido sus módulos de consumo de manera significativa. En Alicante, por ejemplo, éste ha disminuido alrededor de 400 litros por vivienda/día en tan sólo una década. Sin duda, ello tiene que ver con una serie de medidas tomadas por los propietarios (mejora del sistema de riego, cambio de la tipología del jardín, uso de aguas regeneradas, etc.) para aminorar los consumos. Sin olvidar, la incidencia de la coyuntura económica iniciada en España en 2007, que ha agravado aún más si cabe el descenso continuado del gasto de agua que ya venía produciéndose desde mediados de la década del 2000 y que ha favorecido la adopción de iniciativas por parte de los residentes para ahorrar agua y reducir, consiguientemente, el precio pagado por la factura. En esta disminución de los consumos también cabe indicar las campañas, programas y medidas de sensibilización ambiental promovidas por ayuntamientos y empresas encargadas del suministro.

El grupo de establecimientos hoteleros analizados en las ciudades de Alicante y Benidorm muestran como en los hoteles de mayor calidad turística, el gasto de agua por plaza y día se ha incrementado asociado a la introducción de elementos altamente demandantes de agua tanto en las habitaciones como en los servicios comunes (spa, jacuzzi, etc.). Sin embargo, en los de menor categoría, las medidas de ahorro adoptadas para aminorar la factura del agua y el efecto de la crisis se han dejado notar en una reducción del consumo.

La principal conclusión extraída del análisis de la tendencia de consumo de agua por los usos turístico-residenciales es que la crisis económica ha tenido una incidencia relevante en su descenso, pero ésta, no ha sido la única causa. En este sentido, la instalación de dispositivos de ahorro, de electrodomésticos más eficientes en el uso de agua, una mayor concienciación ambiental y el incremento de tarifas de suministro 
han tenido una gran repercusión en el descenso del gasto hídrico. La reducción de los consumos se explica, por tanto, como resultado de una amalgama de causas múltiples e interrelacionadas.

Pero quizás, para valorar el peso de estas medidas y el de la crisis cabrá esperar cómo la situación económica actual cambiará en los próximos años y como ésta, pueda tener una incidencia en el incremento del gasto o, por el contrario, una estabilización del mismo al afianzarse los hábitos personales de ahorro y la implantación de tecnologías más eficientes en el consumo de agua. La mejoría en la economía y en el sector turístico parece que se ha dejado notar en algunos casos estudiados. Si bien, los consumos se encuentran por debajo de los alcanzados en 2005, observa como a partir de 2013 se han recuperado sensiblemente en algunas tipologías urbanas y según municipio. Esto hecho cabría relacionarlo con un mayor nivel de ocupación y frecuentación de las viviendas de los municipios turísticos, especialmente, en las tipologías de marcado carácter turístico-residencial como son bloques de apartamentos, viviendas adosadas y chalés. Ello tiene que ver con los datos del sector turístico, que ha registrado cifras de record en 2016 tanto para España como para la provincia de Alicante.

En cuanto a la previsión futura de la tendencia del gasto de agua es un tema bastante controvertido. Durante los años 2015 y 2016 con respecto a los anteriores se ha producido un ligero repunte del consumo pero, según los técnicos, este hecho se debe a las condiciones climáticas extremas (sequía y olas de calor) durante estos años, que los han calificado como años excepcionales. Sin embargo, el consumo de agua en 2017 respecto a 2016 ha vuelto a disminuir debido en gran medida a que el invierno (diciembre de 2016-marzo de 2017) ha sido una año pluviométricamente bueno en este sector de Alicante y no se han registrado un número elevado de olas de calor ni temperaturas elevadas persistencia como en los dos años anteriores. Finalmente, cabría concluir y preguntarse si la actividad inmobiliaria y la construcción vuelven a repuntar, como evidencian los últimos datos de actividad del sector, como incidirá en el consumo hídrico y si ello, repercutirá en incremento del agua suministrada municipal al haber un mayor número de viviendas conectadas a la red y población atendida.

\section{Bibliografía}

Agencia Valenciana de Turismo (2015): Estadísticas de Turismo. Disponible en: http:/www.turisme.gva.es/opencms/opencms/turisme/es/contents/estadistiquesdeturisme/a nuario/oferta_turistica/oferta_turistica_municipal_comarcal.html (fecha de consulta 10/08/2016).

Baños Castiñeira, C.J., Vera Rebollo, J.F. y Díez Santo, D. (2010): El abastecimiento de agua en los espacios y destinos turísticos de Alicante y Murcia. Investigaciones Geográficas, 51, 81-105. 
Bohdanowicz, P. y Martinac, I (2007): Determinants and benchmarking of resource consumption in hotels-Case study of Hilton International and Scandic in Europe. Energy and Buildings, 39, 82-95.

Burriel, E. (2008): La década prodigiosa del urbanismo español (1997-2006). Scripta Nova, vol. XII, 270 (64). Disponible en: http://www.ub.es/geocrit/sn/sn-270/sn-270-64.htm

Casado-Díaz, M.A., Casado Díaz, A.B. y Casado-Díaz, J.M. (2014): Linking tourism, retirement migration and social capital, Tourism Geographies: An International Journal of Tourism Space. Place and Environment, 16 (1), 124-140.

Castillo-Manzano, J.I., López-Valpuesta, L., Marchena Gómez, M. y Pedregal, D.J. (2013): La gestión del agua y el uso de contadores individuales en el área metropolitana de Sevilla. XX Encuentro de Economía Pública (Sevilla, 31 enero y 1 febrero 2013).

Cohen, R., Wolff, G. y Nelson, B. (2004): The Hidden Costs of California's Water Supply. San Francisco: Natural Resources Defense Council \& Pacific Institute.

Cubillo, F., Moreno, T. y Ortega, S. (2008): Microcomponentes y factores explicativos del consumo doméstico de agua en la Comunidad de Madrid. Colección de Cuadernos de I+D+I. Canal de Isabel II.

Del Moral, Leandro (coord) (1998): El sistema de abastecimiento de agua de Sevilla: análisis de situación y alternativas al embalse del Melonares. (Bilbao: Bakeaz. Nueva cultura del agua. Serie Informes, número 1998/5.) http://polired.upm.es/index.php/boletincfs/article/view/2888/2945

Del Moral-Ituarte, L. y Giansante, C. (2000): Constraints to Drought Contingency Planning in Spain: The Hydraulic Paradigm and the Case of Seville. Journal of Contingencies and Crisis Management, 8, 93-102.

Deoreo, W.B. y Mayer, P.W. (2012): Insights into declining single-family residential water demands. Journal-American Water World Association, 104 (6), 383-394.

Domene, E. y Saurí, D. (2006): Urbanization and water consumption. Influencing factors in the Metropolitan Region of Barcelona. Urban Studies, 43 (9), 1.605-1.623.

Durán (2015): Agua y pobreza en Santiago de Chile. Morfología de la inequidad en la distribución del consumo domiciliario de agua potable. Revista de Estudios Urbanos y Regionales (EURE), vol. 41, 124, 225-246.

Erdogan, N. y Baris, E. (2007): Environmental protection programs and conservation practices of hotels in Ankara, Turkey. Tourism Management, 28, 604-614.

Fernández, S. y Barrado, D.A. (2011): El desarrollo turístico-inmobiliario de la España mediterránea e insular frente a sus referentes internacionales (Florida y la Costa Azul): un análisis comparado. Cuadernos de Turismo, 27, 373-402.

Gabarda Mallorquí, A., García, X., y Ribas Palom, A. (2017): Mass tourism and water efficiency in the hotel industry: A case study. International Journal of Hospitality Management, 61, 82-93.

García, X. (2012): Nous procesos d'urbanització i consum d'aigua per a usos domèstics. Una exploració de relacions a l'àmbit gironí. Universitat de Girona. Tesis Doctoral.

Gil, A. y Rico, A.M. (2007): El problema del agua en la Comunidad Valenciana. Valencia: Fundación de la Comunidad Valenciana Agua y Progreso.

Gil Olcina, A., Hernández Hernández, M., Morote Seguido, A.F., Rico Amorós, A.M., Saurí Pujol, D. y March Corbella, H. (2015): Tendencias del consumo de agua potable en la 
ciudad de Alicante y Área Metropolitana de Barcelona, 2007-2013. Hidraqua, Gestión Integral de Aguas de Levante S.A. y la Universidad de Alicante.

Gössling, S. (2015): New performance indicators for water management in tourism. Tourism Management, 46, 233-244.

Hadjikakou, M., Miller, G., Chenoweth, J., Druckman, A. y Zoumides, C. (2015): A comprehensive framework for comparing water use intensity across different tourist types. $\begin{array}{lllll}\text { Journal of } \quad \text { Sustainable } & \text { Tourism, } & 23 & \text { (10), }\end{array}$ http://dx.doi.org/10.1080/09669582.2015.1044753

Hernández Hernández, M., Saurí Pujol, D. y Morales Gil, A. (2015): Auge y caída de nuevas naturalezas urbanas: plantas ornamentales y expansión turístico-residencial en Alicante. Boletín de la Asociación de Geógrafos Españoles, 2015, 68, 129-157.

Hurd, B.H. (2006): Water conservation and residential landscape: household preferences, household choices. Journal of Agricultural and Resource Economics, 31, 21-32.

Instituto Nacional de Estadística (2011): Demografía y composición del hogar, Cifras INE. Boletín Informativo del Instituto Nacional de Estadística, 3. Disponible en: http://www.ine.es/revistas/cifraine/0309.pdf (fecha de consulta 12/04/2016).

IVE (Instituto Valenciano de Estadística) (2015): Banco de Datos Territorial. Oferta Turística Municipal y Comarcal. Disponible en: http://www.ive.es/ive/bdm/res_optimo.php (fecha de consulta 12/04/2016).

Leichenko, R.M. y Solecki, W.D. (2005): Exporting the American Dream: the globalization of suburban consumption landscapes. Regional Studies, 39(2), 241-253.

Loh, M. y Coghlan, P. (2003): Domestic water use study: Perth, Western Australia 1998-2001. Perth: Water Corporation.

Lute, M.L., Attari, S.Z. y Sherman, S.J. (2015): Don't rush to flush. Journal of Environmental Psychology, 43, 105-111. http://dx.doi.org/10.1016/j.jenvp.2015.06.003

Mantecón, A., Membrado, J.C. y Huete, R. (2016): Fragmentación socio-espacial, inmigración europea y discursos políticos en la provincial de Alicante. Boletín de la Asociación de Geógrafos Españoles, 72, 67-90.

March, H. y Saurí, D. (2016). When sustainable may not mean just: a critical interpretation of urban water consumption decline in Barcelona. Local Environment, http://dx.doi.org/10.1080/13549839.2016.1233528

March, H., Saurí, D. y Rico-Amorós, A.M. (2014): The end of scarcity? Water desalination as the new cornucopia for Mediterranean Spain. Journal of Hydrology, Disponible en: http://dx.doi.org/10.1016/j.jhydrol.2014.04.023

March, H., Morote, A.F., Rico, A.M y Saurí, D. (2017): Household smart metering in Spain: insights from the experience of remote meter reading in Alicante. Sustainability, 9, 582, 118. Doi: $10.3390 /$ su9040582. ISSN: 2071-1050

Membrado, J.C. (2015): Migración residencial y urbanismo expansivo en el mediterráneo español. Cuadernos de Turismo, 35, 259-285.

Ministerio de Fomento (2012): Viviendas visadas. Disponible en: http:/www.fomento.gob.es/BE/?nivel=2\&orden=09000000(fecha de consulta 12/04/2016).

Morote Seguido, A.F. (2014): Tipologías urbano-residenciales del litoral de Alicante: repercusiones territoriales. Ciudad y Territorio. Estudios Territoriales, vol. XLVI, 181, 431-443. 
Morote Seguido, A.F. (2016a): El uso del agua en los jardines de las urbanizaciones del litoral de Alicante. Prácticas de ahorro y sus causas. Investigaciones Geográficas, 65, 135-152. Doi: http://dx.doi.org/10.14198/INGEO2016.65.08

Morote Seguido, A.F. (2016b): La disminución del consumo de agua urbano-turística en la costa de Alicante (España): Una amalgama de causas múltiples e interrelacionadas. Revista de Estudios Regionales, 106, 133-164.

Morote Seguido, A.F. (2017): Espacios ajardinados privados en España y su incidencia en el consumo de agua: Estado de la cuestión. Anales de Geografía de la Universidad Complutense, 37 (2), 415-443.http://dx.doi.org/10.5209/AGUC.57732

Morote Seguido, A.F. y Hernández Hernández, M. (2016a): Jardines y patrones de ajardinamiento en las urbanizaciones del litoral de Alicante. Boletín de la Asociación de Geógrafos Españoles, 70, 31-56.

Morote Seguido, A.F. y Hernández Hernández, M. (2016b): Población extranjera y turismo residencial en el litoral de Alicante (1960-2011): repercusiones territoriales. Revista Latinoamericana de Estudios Urbanos y Regionales (EURE), vol. 42, 126, 55-76.

Morote Seguido, A.F. y Hernández Hernández, M. (2016c): Urban sprawl and its effects on water demand: A case study of Alicante, Spain. Land Use Policy, 50, 352-362.

Morote Seguido, A.F. y Hernández Hernández, M. (2017): El uso de aguas pluviales en la ciudad de Alicante. De Viejas ideas a nuevos enfoques. Papeles de Geografía, 63. DOI: http://dx.doi.org/10.6018/geografia/2017/267531

Morote, A.F., Hernández, M. y Rico, A.M. (2016): Causes of Domestic Water Consumption Trends in the City of Alicante: Exploring the Links between the Housing Bubble, the Types of Housing and the Socio-Economic Factors. Water, 8, 374, 1-18. doi:10.3390/w8090374.

Morote, A.F., Saurí, D. y Hernández, M. (2017): Residential Tourism, Swimming Pools and Water Demand in the Western Mediterranean. Professional Geographer, doi: 10.1080/00330124.2015.1135403.

Olcina, J. y Miró, J. (2016): El clima, recurso básico del turismo alicantino. Canelobre, 66, 1837.

Olcina, J., Baños, C. y Rico, A.M. (2016): Medidas de adaptación al riesgo de sequía en el sector hotelero de Benidorm (Alicante, España). Revista de Geografía Norte Grande, 65, 129-153.

Panagopoulos, G.P. (2014): Assessing the impacts of socio-economic and hydrological factors on urban water demand: A multivariate statistical approach. J. Hydrol., 518, 42-48.

Raya Mellado, P. y Benítez Rochell, J.J. (2002): Concepto y estimación del turismo residencial: aplicación en Andalucía. Papers de Turisme, 31/32, 67-89.

Rico Amorós, A.M. (2007): Tipologías de consumo de agua en abastecimientos urbanoturísticos de la Comunidad Valenciana. Investigaciones Geográficas, 42, 5-34.

Rico Amorós, A.M., Olcina Cantos, J. y Saurí, D. (2009): Tourist land use patterns and water demand: Evidence from the Western Mediterranean. Land Use Policy, 26, 493-501.

Rico Amorós, A.M., Olcina Cantos, J. y Baños Castiñeira, C.J. (2014): Competencias por el uso del agua en la provincia de Alicante: experiencias de gestión en la armonización de usos urbano-turísticos y agrícolas. Documents d'Anàlisi Geogràfica. Vol. 60, 3, 523-548. 
Romano, G., Salvati, N., Guerrini, A. (2014): Estimating the Determinants of Residential Water Demand in Italy. Water, 6, 2929-2945.

Salvà, P. (2002): Foreign immigration and tourism development in Spain's Balearic Islands, Tourism and migration: New relationships between production and consumption. Londres, Kluwer Academic Publishers.

Schleich, J. y Hillenbrand, T. (2007): Determinants of Residential Water Demand in Germany. Working Paper Sustainability and Innovation, 3. Institute Systems and Innovation Research.

Swyngedouw, E. y Williams, J. (2016): From Spain's hydro-deadlock to the desalination fix. Water International, 41, 1, 54-73.

Troy, P., Holloway, D. y Randolph, A. B. (2005): Water use and the built environment: Patterns of water consumption in Sydney, City Futures Research. Report $n^{\circ} 1$. Kensigton: City Futures Research Centre, Faculty of Built Environment, UNSW.

Vera, J.F. (1987): Turismo y Urbanización en el litoral alicantino. Alicante: Instituto de Estudios Juan Gil-Albert.

Vidal, M., Domene, E. y Saurí, D. (2011): Changing geographies of water-related consumption: residential swimming pools in suburban Barcelona. Area, 43,1, 67-75.

\section{Agradecimientos}

Los autores quieren expresar su agradecimiento a la empresa Hidraqua, Gestión Integral de Aguas de Levante, S.A. y a sus diferentes explotaciones, al igual que al personal entrevistado por la acogida y facilitación de información para llevar a cabo esta investigación (Asunción Martínez, Francisco Javier Prieto, Francisco Javier Díez y Enrique Sáez), a Aguas Municipalizadas de Alicante, Empresa Mixta (Francisco Bartual, Eduardo Montero, Antonio Ivorra, Francisco Agulló, Antonio Sánchez, Vicente Juan y César Vázquez). 